\title{
Impact Analysis of Off-board Charger to Power Quality
}

\author{
Yubo Fan, Chunlin Guo, Wenbo Qi, Zheci Tang \\ State Key Laboratory for Alternate Electrical Power System with Renewable Energy Sources, \\ North China Electric Power University, Beijing, China \\ Email: jianhufanyubo@163.com
}

Received January, 2013

\begin{abstract}
In this paper, we tested the entire charging process of a single off-board charger in one charging station in Beijing. Among the testing data, we chose the typical power quality parameters and compared them with national standard. Then we drew conclusions as follows: 1) Electric vehicle battery is the capacitive load. It can export reactive power when charging. 2) In the charging process of the off-board charger, indicators of voltage deviation, frequency deviation, power factor, and voltage distortion rate are qualified. 3) Off-board charger produces odd harmonics in the charging process, and with increasing harmonic order, harmonic content reduces. There is a certain amount of high-order harmonic in off-board charger, mainly distributing around $6650 \mathrm{kHz}$. 4) Generated harmonics of the actual device, the harmonic is mainly reflected in the current, voltage, only a small distortion.
\end{abstract}

Keywords: Electric Vehicles; Charger; Power Quality

\section{Introduction}

With the development of electric vehicles, charging infrastructure also advanced. However, due to the high power charger for charging stations like switching power supply, rectifier, inverter, etc, are usually using power electronic technology, which is a highly non-linear electrical equipment, the large-scale use of it will cause serious power quality problems on the grid. For example, harmonic problem, we have known it for a long time. The flowing harmonic in the grid will result in distortion of the grid voltage and it also limited the application of non-linear system.

At present, some scholars have conducted researches on electric vehicles charging impact on grid, including research on the impact of the increasing electric vehicles on medium or low voltage power network. Issues [1-6] like load, voltage, loss, three-phase unbalance, harmonics etc are included.

But these studies only analyzed the minor part of the charging station about power quality[7-11], there is no comprehensive analysis about all the indicator of power quality. Besides, most research results are concluded from simulation, and they have simplified real operating system. In this case, we can say that their conclusions are questionable.

\footnotetext{
"This work is supported by: National High Technology R\&D Program of China (863Program) (2012AA050804).Key Project of the National Research Program of China (2011BAG02B14), National High Tech-
} nology R\&D Program of China (863 Program) (2011AA05A109)
Therefore, based on the testing data of the single off-board charger charging process, we have systematically analyzed the power quality problems including voltage deviation, frequency deviation, voltage fluctuations and flickers, three-phrase unbalance and harmonics etc. caused by off-board charger systematically and drawn conclusions.

\section{Power Quality Indicators}

\subsection{Chinese National Standard Limit}

1) Voltage deviation

According to GB/I2325-2008 Power quality-Deviation of supply voltage, the allowable deviation of three -phrase supply power that below $20 \mathrm{kV}$ is $\pm 7 \%$ of system rated voltage.

2) Frequency deviation

The nominal frequency of the power system in China is $50 \mathrm{~Hz}$. According to GB/T15945-1995 Quality of electric energy supply-Permissible deviation of frequency for power system, the allowable frequency deviation of the power system is $\pm 0.2 \mathrm{~Hz}$

3) Voltage fluctuation

According to GB12326-2008 Power quality--Voltage fluctuation and flicker, the voltage fluctuations of common connection points ranked $0.38 \mathrm{kv}$ and $10 \mathrm{kv}$ caused by impact load should below $2 \%$.

4) Three-phrase unbalance

Three-phrase unbalance refers to three-phase voltage (or current) amplitude is inconsistent and exceed the 
specified range in the power system. The unbalance factor expression,

$$
\varepsilon_{u}=\frac{U_{2}}{U_{1}} \times 100 \%
$$

where, $U_{1}$-the R.M.S. of three-phrase voltage positivesequence component, $\mathrm{V}$;

$U_{2}$ - the R.M.S. of three-phrase voltage negative-sequence component, $\mathrm{V}$.

According to GB/T15543-2008 Power quality-Admissible three-phrase voltage unbalance factor, the common voltage unbalance limit of every user is $1.3 \%$, i.e., the side normal voltage unbalance of $0.38 \mathrm{kv}$ caused by charger should below $1.3 \%$.

5) Harmonic voltage

The total ratio of voltage harmonic distortion refers to the percentage of higher harmonic voltage RMS and the fundamental voltage RMS. China have set a standard for allowable values of harmonic voltage of the power supply.

According to GB/T14549-93 Quality of electric energy supply-Harmonics in public supply network, the total harmonic distortion rate limit is $5.0 \%$ and $4.0 \%$, the corresponding harmonic voltage is $0.38 \mathrm{kv}$ and $10 \mathrm{kv}$. The following table shows that harmonic voltage in the in- point should below values in Table 1.

6) Harmonic current

As to public electric network of $0.38 \mathrm{kv}$, when the reference short-circuit capacity is 10 MVA, Harmonic current permissible value shown in Table 2.

When the reference short-circuit capacity is not 10 MVA, harmonic current allowed values are permitted in accordance with the size of the actual minimum shortcircuit capacity scaling.

$$
I_{h i}=h\left(h_{T} / h_{I}\right)^{1 / \partial}
$$

where, $I_{h i}$ means the RMS of each harmonic current converted; $h$ represents the allowed values of harmonic current acquired from power system; $h_{T}$ means the minimum short-circuit capacity of single set of devices; $h_{I}$ means the reference short-circuit capacity of point of common coupling; $\partial$ represents phase superposition coefficients, $\partial$ 's value of each harmonic current shown in Table 3:

With $0.38 \mathrm{kV}$ electric utility network, grid system short-circuit capacity of 10 MVA (the benchmark short circuit capacity), according to GB/T14549-93 quality of electric energy supply--harmonics in public supply network, the utility grid injected harmonic current component (root mean square value) should not exceed in exemplar 4-2 (harmonic current permissible value of injected into the common connection point) in the allowable value (as shown in Table 4).

Since the Test points of $0.4 \mathrm{kV}$ bus at a minimum short-circuit current of $10 \mathrm{kA}$, so the minimum shortcircuit capacity of the low-voltage side of the transformer is [11]:

$$
S_{s c}=\sqrt{3} \times 0.4 \times 10=6.928(M V A)
$$

The actual minimum of short circuit capacity is $S_{T}=6.928 M V A$, Which is use to compute harmonic finite value of the common points, and from that we got Table 5.

Table 1. Harmonics voltage limit value in public supply network ( phrase voltage).

\begin{tabular}{cccc}
\hline \multirow{2}{*}{$\begin{array}{c}\text { System Rated } \\
\text { Voltage (KV) }\end{array}$} & $\begin{array}{c}\text { THD Urel to h1 } \\
(\%)\end{array}$ & \multicolumn{2}{c}{$\begin{array}{c}\text { Harmonic Voltage } \\
\text { Ratio }(\%)\end{array}$} \\
\cline { 3 - 4 } & & Odd & Even \\
\hline 0.4 & 5.0 & 4.0 & 2.0 \\
10 & 4.0 & 3.2 & 1.6 \\
\hline
\end{tabular}

Table 2. IEC-3-4 Harmonic current permissible value.

\begin{tabular}{ccccccc}
\hline Harmonic Order $\mathrm{n}$ & 5 & 7 & 11 & 13 & 17 & 19 \\
\hline $\begin{array}{c}\text { Permissible Harmonic } \\
\text { Current }\left(\mathrm{I}_{\mathrm{n}} / \mathrm{I}_{1}\right) / \%\end{array}$ & 9.5 & 6.5 & 3.1 & 2.0 & 1.2 & 1.1 \\
\hline
\end{tabular}

Table 3. $\partial$ 's value of each harmonic current.

\begin{tabular}{|c|c|c|c|c|c|c|c|c|c|c|c|c|c|}
\hline \multirow{2}{*}{ Rated Voltage $/ \mathrm{kV}$} & \multirow{2}{*}{$\begin{array}{l}\text { Reference short-circuit } \\
\text { capacity / MVA }\end{array}$} & \multicolumn{12}{|c|}{ Harmonic order and harmonic current permissible value (A) } \\
\hline & & 2 & 3 & 4 & 5 & 6 & 7 & 8 & 9 & 10 & 11 & 12 & 13 \\
\hline \multirow{5}{*}{0.38} & & 78 & 62 & 39 & 62 & 26 & 44 & 19 & 21 & 16 & 28 & 13 & 24 \\
\hline & & \multicolumn{12}{|c|}{ Harmonic order and harmonic current permissible value (A) } \\
\hline & 10 & & & & & & & & & & & & \\
\hline & & 14 & 15 & 16 & 17 & 18 & 19 & 20 & 21 & 22 & 23 & 24 & 25 \\
\hline & & 11 & 12 & 9.7 & 18 & 8.6 & 16 & 7.8 & 8.9 & 7.1 & 14 & 6.5 & 12 \\
\hline
\end{tabular}

\begin{tabular}{cccccc}
\hline Harmonic Order $\mathrm{n}$ & 5 & 7 & 11 & 13 & $>13$ \\
\hline$\partial$ & 1.2 & 1.4 & 1.8 & 1.9 & 2.0 \\
\hline
\end{tabular}

Table 4. Harmonic current permissible value of injected into the point of common coupling. 
Table 5. Measured limit value of harmonic current.

\begin{tabular}{cccccccc}
\hline $\begin{array}{c}\text { Harmonic } \\
\text { Order n }\end{array}$ & 3 & 5 & 7 & 11 & 13 & 17 & 19 \\
\hline $\begin{array}{c}\text { Harmonic } \\
\text { Current } / \mathrm{A}\end{array}$ & 4.03 & 5.06 & 5.14 & 5.27 & 4.93 & 4.00 & 3.56 \\
\hline
\end{tabular}

\subsection{Standard Comparison between Chinese and IEC's}

Table 6 shows a comparison of power quality between national and IEC standards. The table shows that the national standards allowable values of power quality below the IEC standard allowable value, so if they meet the requirements of the national standards of China, they must meet the IEC standard.

\section{Test Description}

The test is aimed at a single off-board charger (parameters in Table 7) whose rated power is $15 \mathrm{~kW}$ in an EV charging station of Beijing. A power quality testing is carried out through the entire charging process of $8 \mathrm{~T}$ sanitation truck battery power $(200 \mathrm{AH} / 96 \mathrm{~V})$ in the charging station.

The three-stage charging method is used in the charging process of the $8 \mathrm{~T}$ sanitation truck battery power $(200$ $\mathrm{AH} / 96 \mathrm{~V})$. The first stage is the constant current limit pressure mode, the charging current $\mathrm{I}=60 \mathrm{~A}$, the limit voltage $\mathrm{U}=103 \mathrm{~V}$; the second stage is a constant current limiting mode, the charging voltage $\mathrm{U}=103 \mathrm{~V}$, the limit current $\mathrm{I}=20 \mathrm{~A}$; the third stage is charging stopped, the charge cut-off current is $0.1 \mathrm{C}(20 \mathrm{~A})$. The monitor analyzer of the test is American FLUKE three-phase power quality analyzer (Model: Fluke1760 Basic). Continuous recording of three-phase data is on the $\mathrm{AC}$ side of charger for the whole process of charging.

Test point is selected in the AC input side of the charger; the testing diagram is shown in Figure 1.

Table 6. A comparison of power quality between national and IEC standards.

\begin{tabular}{|c|c|c|}
\hline Power quality indicators & Chinese national standard & IEC \\
\hline Voltage deviation & $\begin{array}{l}\text { the rated voltage is } \pm 7 \% \text { of the high-voltage power supply and } \\
\text { low voltage power users of } 10 \mathrm{kV} \text { and below }\end{array}$ & No standard \\
\hline Frequency deviation & $\begin{array}{l}\text { the allowable value of frequency deviation of power system is } \pm \\
0.2 \mathrm{~Hz} \text {; when the compatible value is larger, the deviation value } \\
\text { can be as large as } \pm 0.5 \mathrm{~Hz}\end{array}$ & $\begin{array}{l}\text { Short-term changes is } \pm 1 \mathrm{~Hz} \text {, and the steady-state } \\
\text { is smaller }\end{array}$ \\
\hline Voltage harmonics & $\begin{array}{l}\text { Total harmonic distortion is } 5 \% \text {; } \\
\text { When the nominal voltage of power grid is } 10 \mathrm{kv} \text {, correspond- } \\
\text { ingly, Odd harmonic is } 3.2 \% \text {, } \\
\text { Even harmonic is } 1.6 \% \text {, } \\
\text { Total harmonic distortion is } 4 \% \text {; }\end{array}$ & $\begin{array}{l}\text { Thirteenth harmonic } 3 \% \text {, } \\
\text { Total harmonic distortion } 8 \% \text {; } \\
\text { As to very short effect( within } 3 \mathrm{~s} \text { seconds), } \\
\text { compatible level equals to } \mathrm{K} * \text { the above values, } \\
\left.\mathrm{K}=1.3+0.7 / 45^{*} \text { (h- } 5\right), \mathrm{THD}=11 \% \text { 。 }\end{array}$ \\
\hline $\begin{array}{l}\text { Voltage fluctuations and } \\
\text { flickers }\end{array}$ & $\begin{array}{l}\text { The voltage fluctuations are not larger than } 3 \% \text { of supply voltage } \\
\text { in common conditions; short term flicker }(10 \mathrm{~min}) \mathrm{p}_{\mathrm{st}}=1 \text {, long } \\
\text { term flicker }(2 \mathrm{~h}) \mathrm{p}_{\mathrm{lt}}=0.8\end{array}$ & $\begin{array}{l}\text { The voltage fluctuations are not larger than } 3 \% \text { of } \\
\text { the nominal supply voltage;short term flicker }(10 \\
\text { min }) \mathrm{p}_{\mathrm{st}}=1 \text {,long term flicker }(2 \mathrm{~h}) \mathrm{p}_{\mathrm{lt}}=0.8\end{array}$ \\
\hline Three-phrase unbalance & $\begin{array}{l}\text { The amissible factor is } 2 \% \text { in points of common coupling in the } \\
\text { common conditions of power system, short time is no longer } \\
\text { than } 4 \% \text {, unbalance factor caused by users is } 1.3 \%\end{array}$ & $\begin{array}{l}\text { negative-sequence component is } 2 \% \text { of posi- } \\
\text { tive-sequence component, it can reach } 3 \% \text { in } \\
\text { certain place }\end{array}$ \\
\hline
\end{tabular}

Table 7. Off-board charger technical parameters.

\begin{tabular}{cc}
\hline Heading & off-board charger \\
\hline Technical Specifications & HEV-Z-ER125 A/120 V \\
Input voltage & AC380 V $\pm 15 \%$ \\
AC input frequency & $45-65 \mathrm{~Hz}$ \\
Output voltage & DC120V (Adjustable) \\
Output current & $125 \mathrm{~A}$ \\
Maximum output power & $15 \mathrm{~kW}$ \\
\hline
\end{tabular}

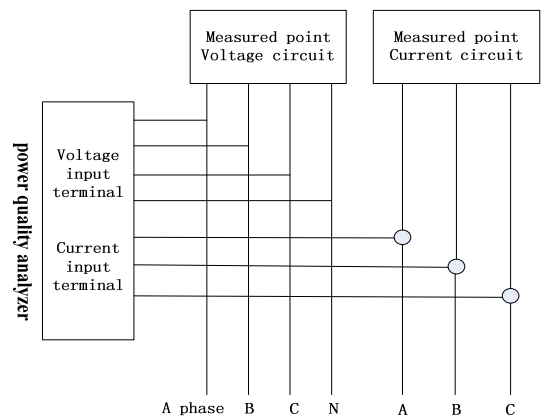

Figure 1. Test wiring diagram. 


\section{Test Outcome}

1) Startup surge

It takes the charger about 32 seconds from start to the stage of constant-current limit voltage charging, but great surge current will be produced in the moment of starting. The above figure indicates that the current surge produced by single charger starting is very large: the amplitude can up to $20.3 \mathrm{~A}$. After the chargers are constructed in large scale, the current surge produced by many chargers starting at the same time will have very great impact on the power grid (as shown in Figure 2).

2) Voltage RMS and current RMS

When charger provides normal charging to the power battery, the voltage measured by power quality analyzer is $237 \mathrm{~V}$, and the current $9.2 \mathrm{~A}$.

3) Power and power factor

Conclusion: Over $95 \%$ of the charging is constant power charging. Reactive powers of the test points are negative, indicating the presence of reactive power backfeed and the capacitive load. The charger is stable, the power factor when charger stably running is almost 1 , which is in line with the requirements of the relevant national standards (as shown in Figure 3).

4) Grid frequency deviation

Figure 4 shows the measured grid frequency trends, and also indicates that the maximum frequency deviation of charger network side is -0.018 , which is within the allowable value of GB $( \pm 0.2 \mathrm{~Hz})$ and so in line with national standards.

5) Voltage Deviation

Taking phase A as an example. As can be seen from Figure 5, the maximum of voltage upper deviation is of about $4 \%$ and that of the voltage lower deviation is zero. Both of them are less than the limit of $7 \%$. So a single charger charging will not cause the AC side voltage deviation exceeded.

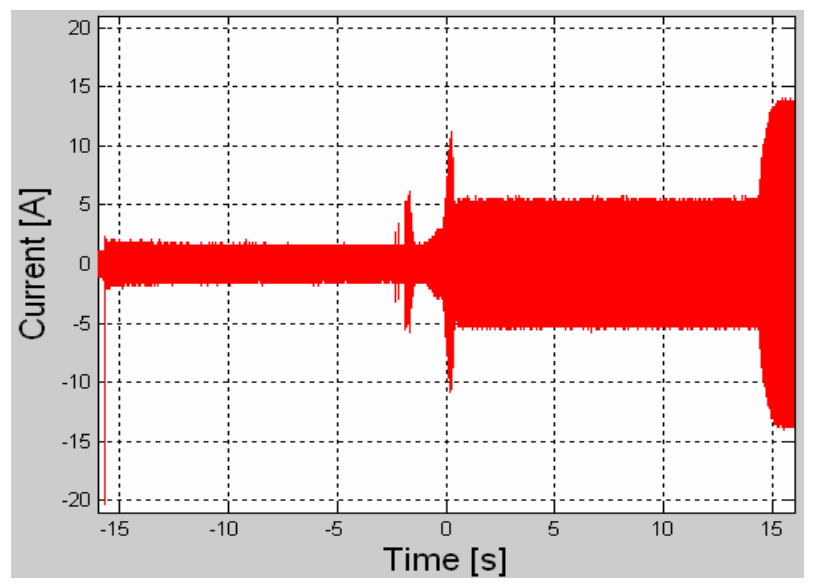

Figure 2. The surge current waveform when charger starting.

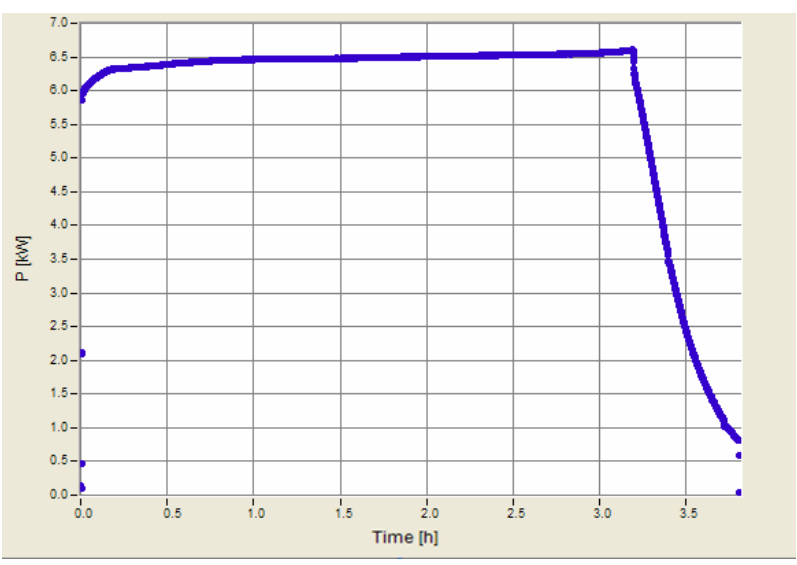

(a) Charger input active power curve

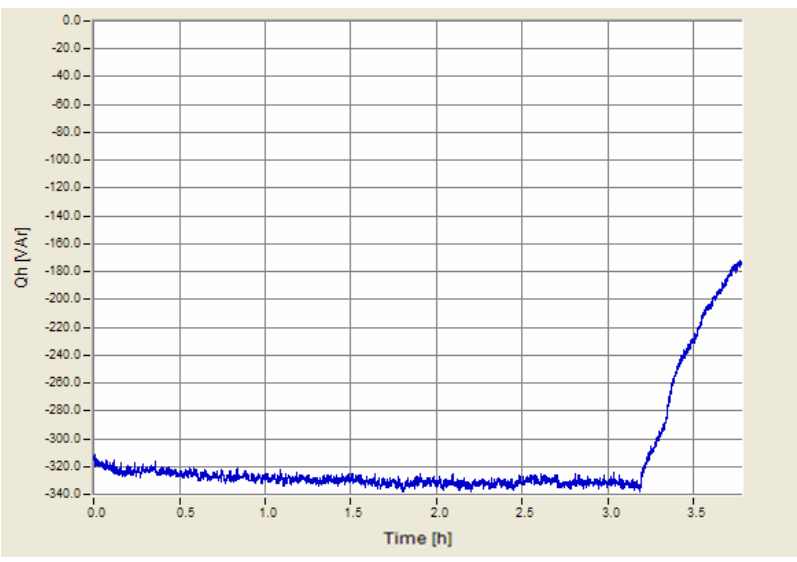

(b) Charger input reactive power curve

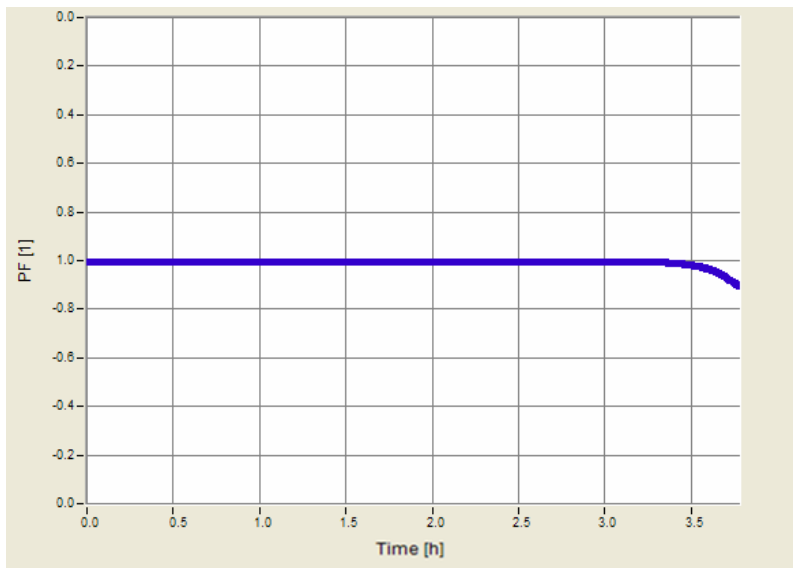

(c) Charger power factor curve

Figure 3. Power and power factor.

6) Voltage fluctuation

Figure 6 shows the maximum voltage fluctuation produced by a single charger $\mathrm{AC}$ side is $2.4 \%$, which exceeds the GB limit of $2 \%$. However, the maximum variation in voltage produced in more than $95 \%$ of the whole charging process is within limits. So the single charger charging substantially will not cause excessive voltage fluctuations in the AC side. 


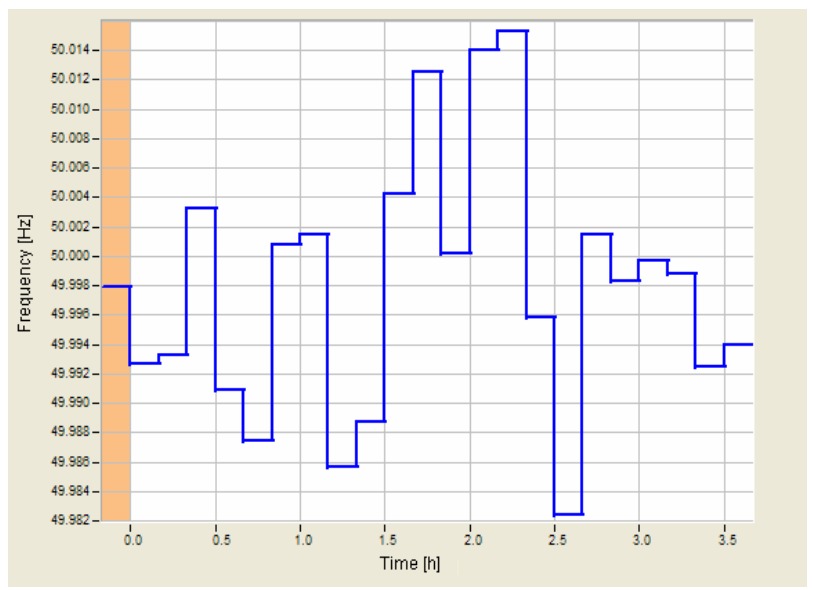

Figure 4. The charger network side frequency curve.

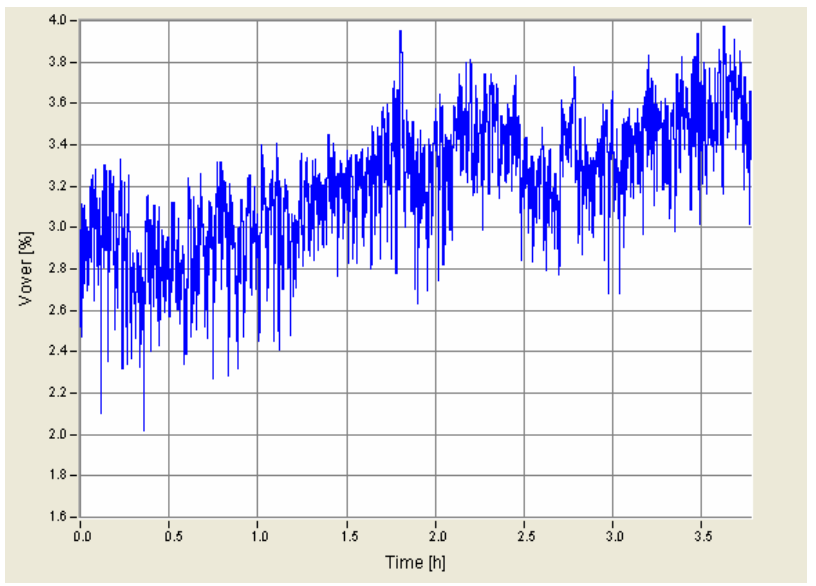

(a) The voltage upper deviation

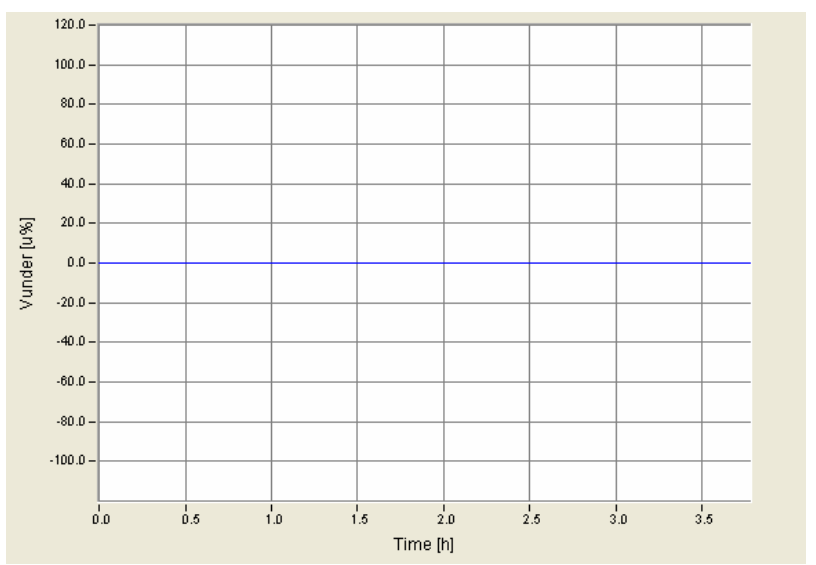

(b) The voltage lower deviation

Figure 5. Voltage deviation.

7) Three-phase unbalance

Figure 7 shows that the three-phase voltage unbalance factor is below $0.4 \%$, far less than the GB $1.3 \%$. So the three-phase unbalance of charger network side is in line with the provisions of the relevant national standards.

8) Harmonic voltage
Figure 8(a) is a period of voltage waveform (Urms = $242 \mathrm{~V}$, Irms $=9.86 \mathrm{~A}$ ) in power stationary phase captured by the oscilloscope Figure 8 shows that a single charger running has inconspicuous impact on the network side voltage. $T H D_{u}$ is less than $2 \%$, and the odd harmonics and even harmonics ratios are both no more than $2 \%$. So the charger network side harmonic voltage is in line with the provisions of the relevant national standards.

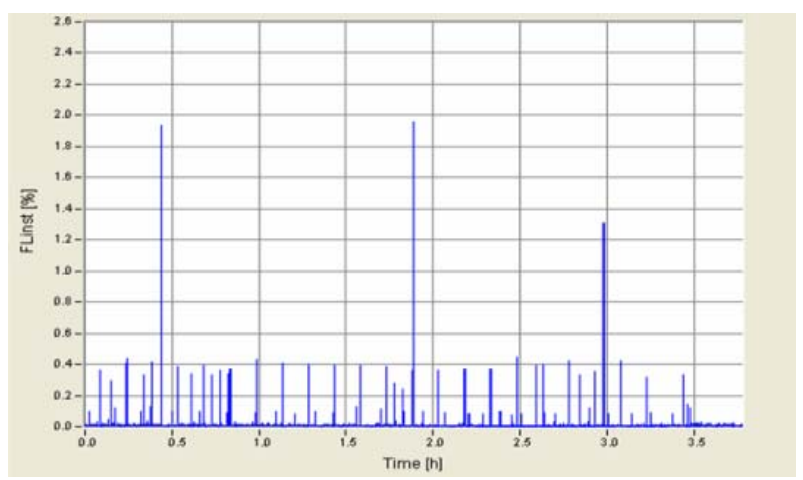

Figure 6. The charger AC side voltage fluctuations diagram of the entire charging process.

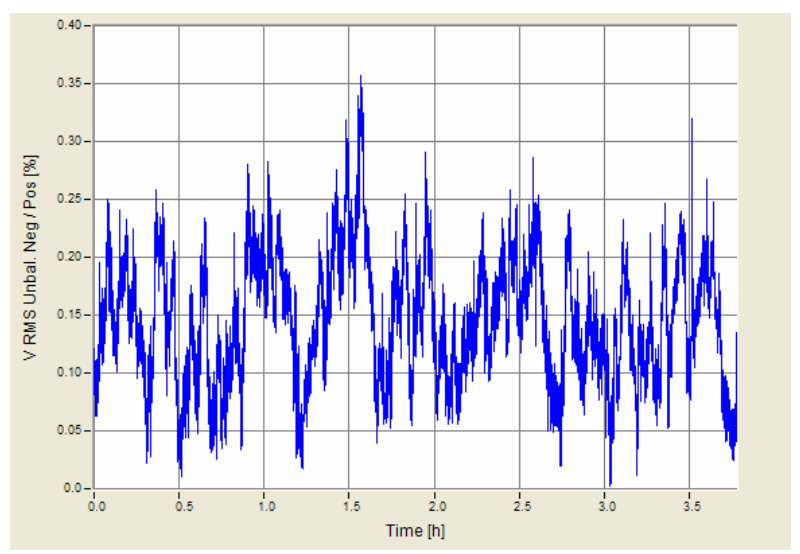

Figure 7. Time-varying trend of three-phase voltage unbalance factor.

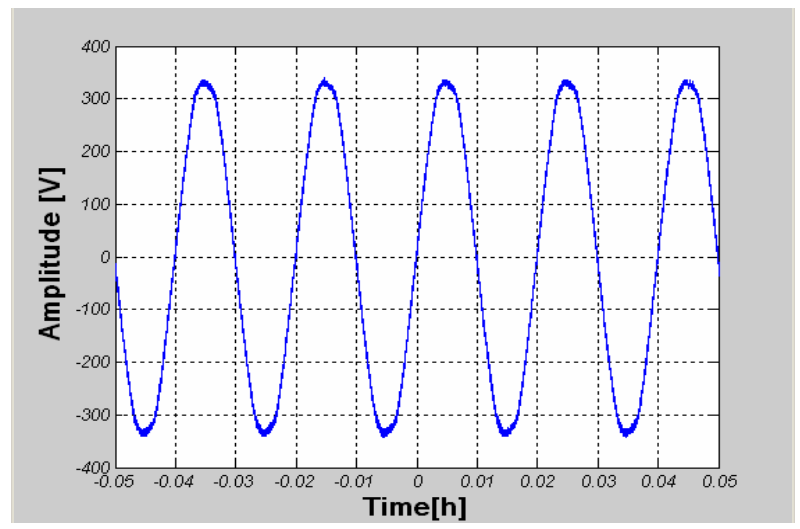

(a) The voltage waveform of charger AC side 


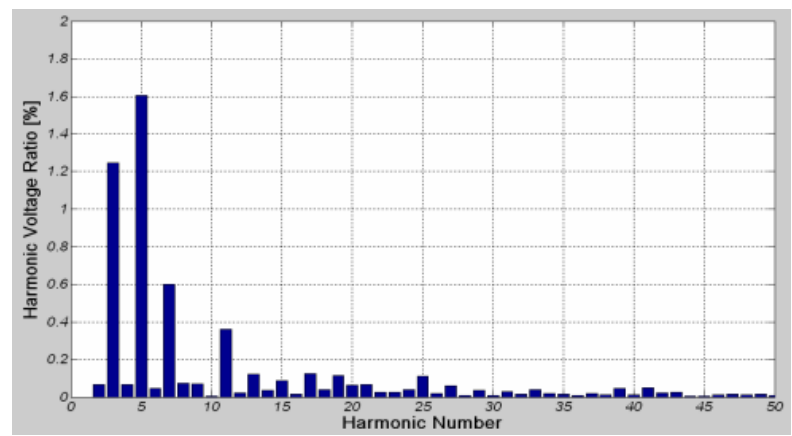

(b) Charger AC side harmonic voltage spectrum

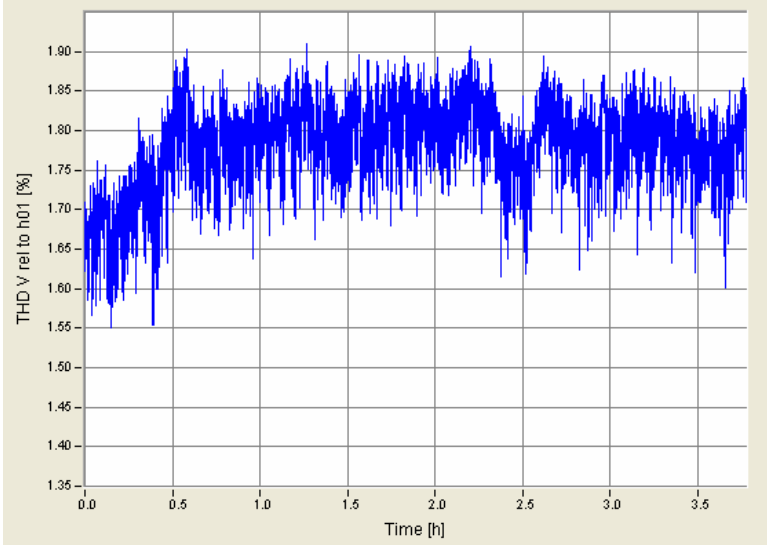

(c) The total harmonic voltage distortion rate of the completed charging process

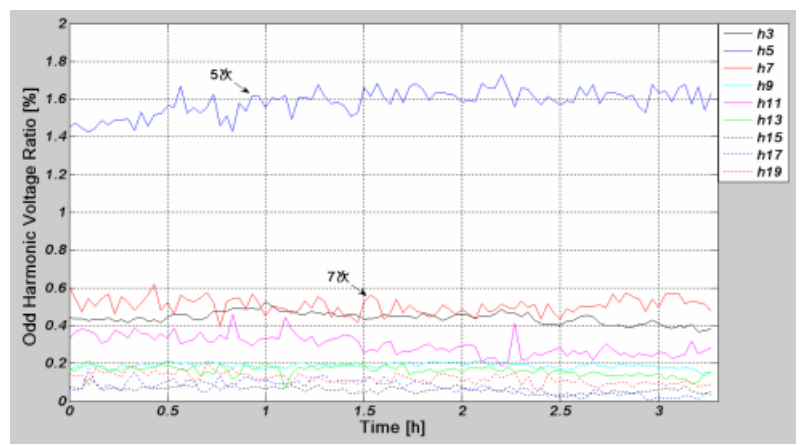

(d) The time-varying trend of the odd harmonic voltage ratio in the entire charging process

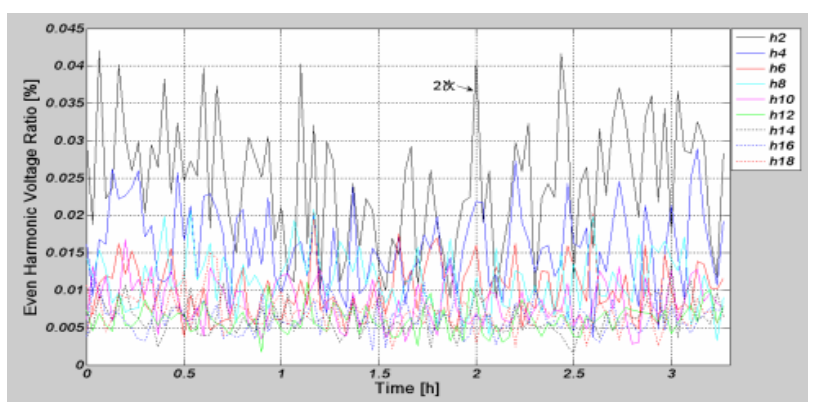

(e) The time-varying trend of the even harmonic voltage ratio in the entire charging process

Figure 8. Harmonic voltage.

9) Harmonic Current
Figure 9(a) is a period of voltage waveform (Urms = $242 \mathrm{~V}$, Irms $=9.86 \mathrm{~A}$ ) in power stationary phase captured by the oscilloscope.

Figure 9 shows that in even harmonics, single charger generates twice maximum $I_{h 2}$ sometimes the amplitude even ups to $0.11 \mathrm{~A}$, which may have some impact on the grid; In odd harmonics, single charger generates 3 times minimum harmonic, mainly generating $6 \mathrm{k} \pm 1$ times harmonic, $\mathrm{k}=1,2,3, \ldots$, that is, 5 times, 7 times, 11 times, 13 times, 17 times, 19 times, .... The higher the order, the smaller the amplitude, wherein the $I_{h 5}$ maximum, and the $I_{h 5}$ second.

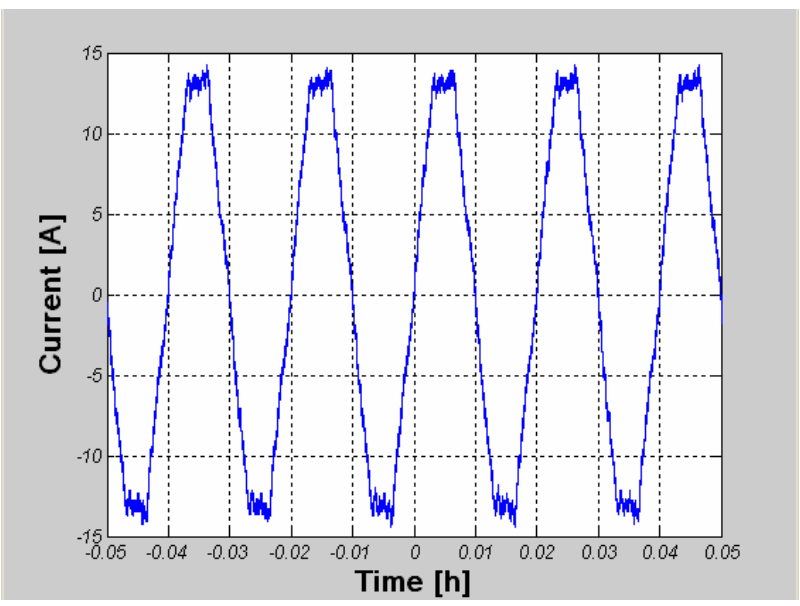

(a) Charger AC side current waveform

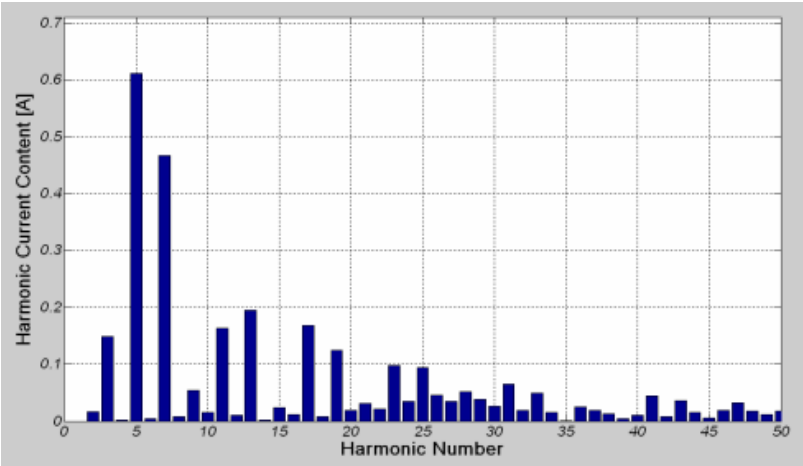

(b) Charger AC side harmonic current spectrum

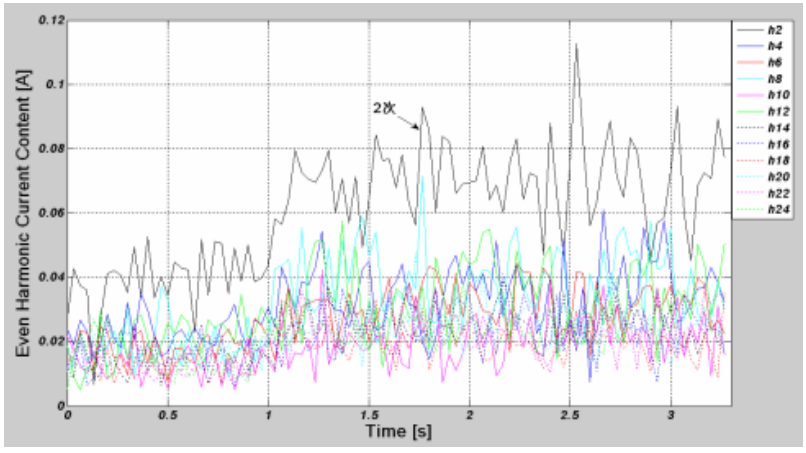

(c) Time-varying trend of the even harmonic current content throughout the charging process 


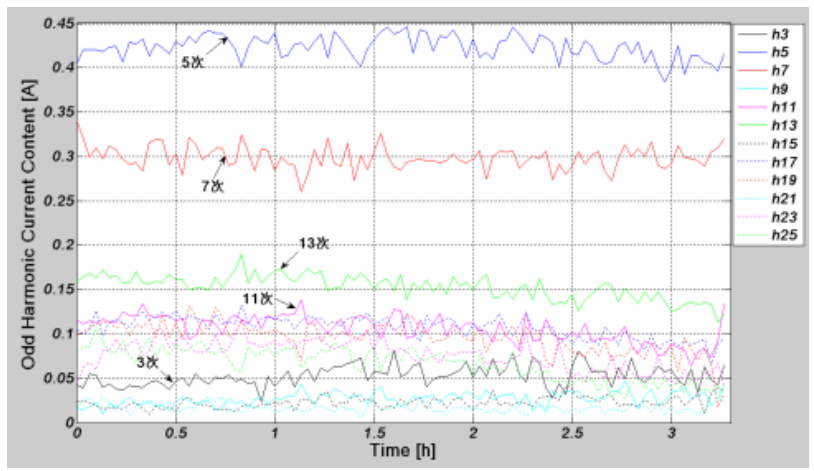

(d) Time-varying trend of the odd harmonic current content throughout the charging process

Figure 9. Harmonic Current.

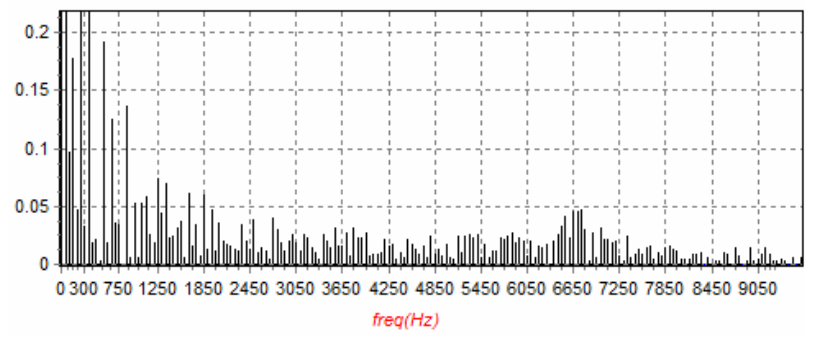

Figure 10. Charger AC side 0-10 $\mathrm{kHz}$ current harmonic spectrum.

10) Higher Harmonic Phenomenon

Conclusion: The preceding analysis shows that the low-order harmonics of the off-board charger is very low, which is in line with relevant international standards. But Figure 10 shows that there is also higher harmonic, mainly distributing around $6650 \mathrm{kHz}$

\section{Conclusions}

After monitoring the charging process of single-board charger in electric vehicles charging station, and evaluating the testing results, we can draw conclusions as follows:

1) Electric vehicle battery is the capacitive load. It can export reactive power when charging.

2) In the charging process of the off-board charger, indicators of voltage deviation, frequency deviation, power factor, and voltage distortion rate are qualified.

3) Off-board charger produces odd harmonics in the charging process, and with increasing harmonic order, harmonic content reduces. There is a certain amount of high-order harmonic in off-board charger, mainly distributing around $6650 \mathrm{kHz}$.

4) Generated harmonics of the actual device, the harmonic is mainly reflected in the current, voltage, only a small distortion.

In fact it also shows that in the actual grid operation, to ensure that the grid power quality standards, vehicle charging station will consider providing compensation device and filtering device in associated distribution system.

\section{REFERENCES}

[1] K. Clement Nyns, E. Haesen and J. Drisen, "The Impact of Charging Plug-in Hybrid Electric Vehicles on a Residential Distribution Grid," IEEE Transaction on Power System, Vol. 25, No. 1, 2010, pp. 371-380.doi:10.1109/TPWRS.2009.2036481

[2] G. A. Putrus, P. Suwanapingkaral, D. Johnston, et al., Impact of Electric Vehicles on Power Distribution Networks, Proceeding of IEEE Vehicle Power and Propulsion Conference, September 7-10, 2009, Dearborn, MI, USA, 827-831.

[3] S. N. Shao, M. Pipattanasomporn and S. Rahman, "Challenges of PHEV Penetration to the Residential Distribution Network," Proceeding of IEEE Power \& Energy Society General Meeting, Calgary, Canada, July 26-30, 2009.

[4] J. Taylor, A. Maitra, M. Alexander, et al., "Evaluation of the Impact of Plug-in Electric Vehicle Loading on Distribution System Operation,"Proceeding of IEEE Power \& Energy Society General Meeting, Calgary, Canada, July 26-30, 2009.

[5] C. Roe, F. Evanelos, J. Melsel, et al., "Power System Level Impacts of PHEVs," Proceeding of the $42^{\text {nd }}$ Hawaii International Conference on System Sciences,Hawaii, HI,USA, January 5-8, 2008.

[6] M. Basu, K. Gaughan and E. Coyle, "Harmonic Distortion Caused by PHEV Battery Chargers in the Distribution Systems Network and Its Remedy," Proceeding of the $39^{\text {th }}$ International University Power Engineering Conference,Bristol, UK, September 6-8, 2004.

[7] M. Y. Xu, X. H. Mu, H. Zhang, Y. He, M. J. Zhang and $X$. G. Chen, "Analysis of the Influence the Electrical Vehicle Charging Station to the Grid Harmonics," Heilongjiang Electric Power, No. 1, 2012.

[8] L. L. Ma and J. Q. Zhang, "Study on Electric Vehicle Charging Device Model Based on PSCAD and Harmonic Analysis," Shanxi Electric Power, Vol. 7, 2012, pp. 28-32.

[9] M. Huang, S. F. Huang and J. C. Jiang, "Harmonic Study of Electric Vehicle Chargers," Journal of Beijing Jiaotong University, Vol. 5, 2008.

[10] Q. Zhang, W. J. Han, J. H. Yu, C. Y. Li and L. F. Shi, "Simulation Model of Electric Vehicle Charging Station and the Harmonic Analysis on Power Grid," Transactions of China Electrotechnical Society, Vol. 2, 2012.

[11] Q. Liu, "Charging Modes of Electric Vehicle and the Impact Analysis of Charging Station to Power Quality on Power Grid," China High-Tech Enterprises, Vol. 27, 2011. 